\title{
ESTABILIDAD ESTRUCTURAL DEL SISTEMA DRAGADOS-PLASTBAU
}

\author{
José Quereda Laviña, IETcc/CSIC \\ Edelmiro Rua Alvarez, Labor. Estructuras (Esc. Caminos, Madrid) \\ José Maria Conde Salazar, Geotecnia y Cimientos, S. A. \\ Jesús Rodriguez Santiago, Dragados y Construcciones, S. A.
}

\section{INTRODUCCION}

El análisis del comportamiento estructural del sistema constructivo Dragados-Plastbau exigió llevar a cabo un estudio de cada uno de sus elementos, muros y forjados, y del conjunto de ellos formando parte de los edificios.

El forjado Cádiz es una losa nervada de hormigón armado y por lo tanto su comportamiento se supuso conocido. Los muros portantes D-P II pueden asimilarse a pórticos de hormigón formados por sus pilares y vigas, ya que en principio no se cuenta con la colaboración resistente de las capas de microhormigón armado. Sin embargo tuvo que justificarse la viabilidad de poder hormigonar in situ con garantia suficiente sus pilares de 0,15 $\times 0,16 \mathrm{~m}$ de sección al ser estas dimensiones inferiores a las admitidas en la Norma $\mathrm{EH}-82$ (1). Los elementos D-P I utilizados como forjados de cubierta de luz pequeña o como muros portantes exigieron una experimentación extensa para poder justificar su comportamiento estructural al no poder asimilarse a otros elementos estructurales conocidos.

El conjunto formado por forjados Cádiz y muros portantes D-P II tienen un comportamiento estructural similar al de algunas tipologias estructurales existentes y no fue preciso llevar a cabo ninguna experimentación. Sin embargo, las estructuras formadas por muros D-P I y forjados Cádiz o forjados de cubierta D-P I resultaban en cierto modo desconocidas y ello obligó a desarrollar unos estudios experimentales que se plantearon en dos fases. En la primera se ensayaron las uniones entre forjados y muros interiores o exteriores y en la segunda se construyeron modelos a escala real, formados por muros y forjados, que se ensayaron en laboratorio y en campo.
Los estudios y la experimentación realizada, que se llevaron a cabo de acuerdo a recomendaciones y normas de ensayo (2), (3), (4), (5), han permitido establecer los criterios para el diseño y cálculo de la estructura de los edificios construidos con este sistema. En este artículo se resume la experimentación realizada, algunos de los resultados obtenidos y las conclusiones que han quedado recogidas en los Documentos de Idoneidad Técnica obtenidos.

\section{ENSAYOS CON ELEMENTOS AISLADOS}

\subsection{Muros D-P II}

La necesidad de tener que hormigonar in situ los pilares de estos muros que habitualmente tienen alturas comprendidas entre los 2,50 y $3,00 \mathrm{~m}$ y que a veces se arman con cuatro redondos de 10 ó $12 \mathrm{~mm}$ de diámetro y $\mathrm{E} \varnothing 6 / 0,15$ aconsejó llevar a cabo un estudio previo sobre la viabilidad de esta operación. En los exteriores del laboratorio de Geocisa de Coslada se hormigonaron un conjunto de muros con más de cuarenta pilares de 2,80 $\mathrm{m}$ de altura armados con 4 redondos $\varnothing 12$ y EØ6/0,15 empleándose diversos tipos de mezclas y diferentes sistemas de puesta en obra. Posteriormente se descubrieron los pilares para realizar una inspección visual del hormigón obtenido lo que permitió seleccionar el tipo de mezclas y el sistema de puesta en obra más idóneos. De algunos de los pilares seleccionados se extrajeron testigos de $60 \mathrm{~mm}$ de diámetro y $120 \mathrm{~mm}$ de longitud que se rompieron a compresión, proporcionando un valor medio de rotura de $255 \mathrm{kp} / \mathrm{cm}^{2}$ con un hormigón cuya resistencia media en probeta enmoldada de $15 \times 30 \mathrm{~cm}$ fue de $225 \mathrm{kp} / \mathrm{cm}^{2}$.

Otros pilares fueron preparados y cortados a una longitud de $2,50 \mathrm{~m}$ para ensayarse a com- 


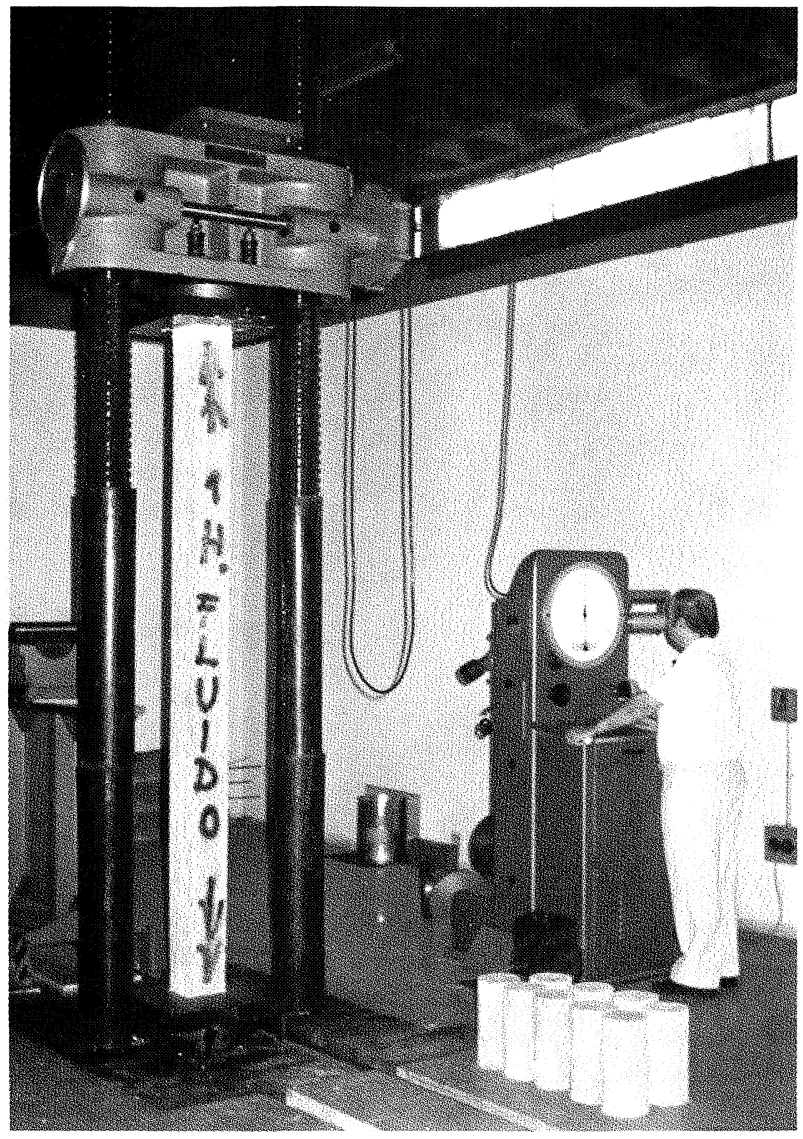

Fig. 1. - Ensayo a compresion de un pilar de un muro D-P II.

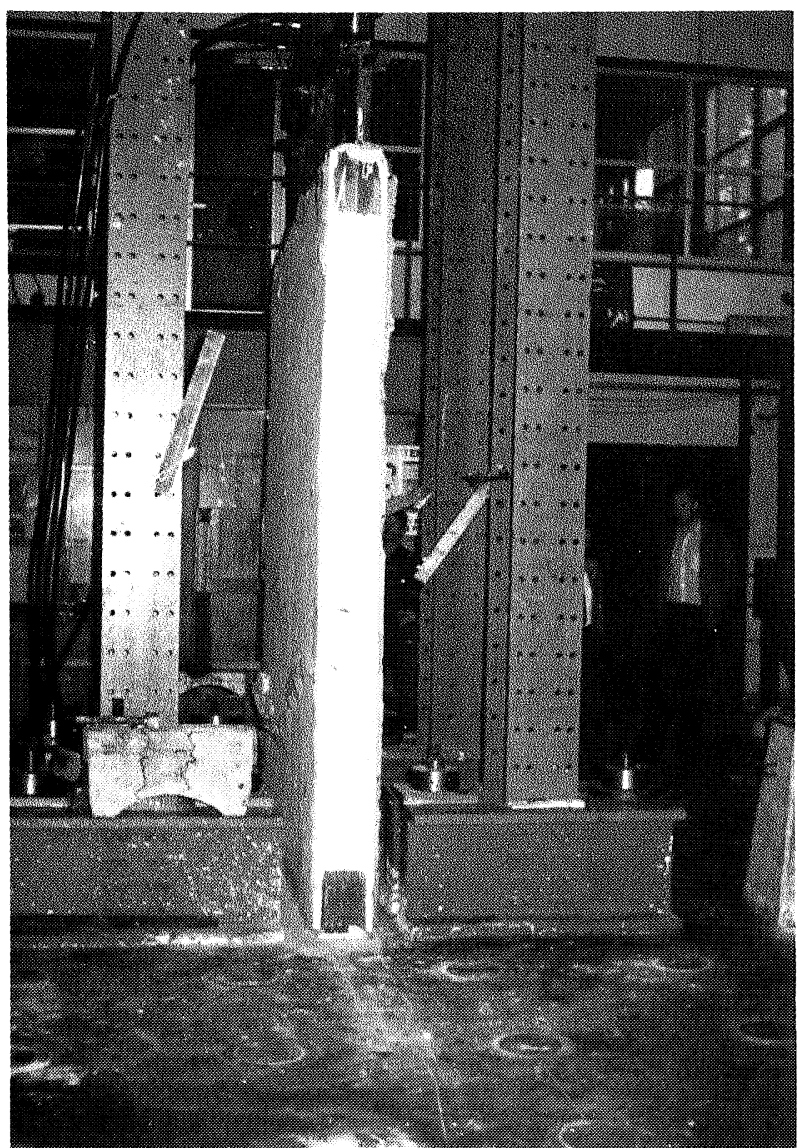

Fig. 2. - Ensayo a compresion de un muro D-P II.

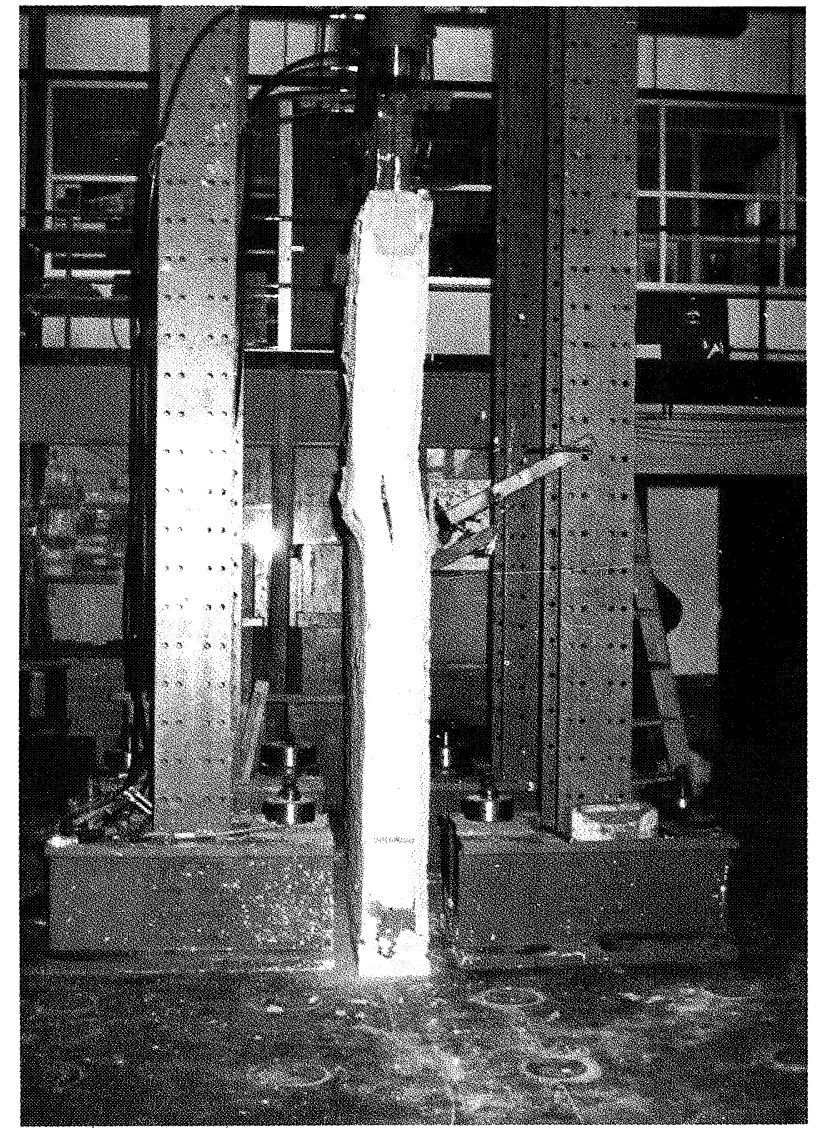

Fig. 3. - Rotura de un muro D-P II.

presión en el laboratorio de Estructuras de la Escuela de Caminos de Madrid. La carga de rotura media obtenida en una prensa con ambos platos articulados (fig. 1) fue un $10 \%$ superior a la deducida de los cálculos realizados a partir de la resistencia de los materiales empleados y suponiendo una solicitación de compresión simple en los pilares, a la vista de la ausencia de pandeo observada durante los ensayos.

De estos estudios se ha deducido la conveniencia de utilizar hormigones con $12 \mathrm{~mm}$ de tamaño máximo de árido, con conos de Abrams de 15 a $20 \mathrm{~cm}$ obtenidos mediante la utilización de superplastificantes y con granulometrias de áridos similares a las de los hormigones bombeables. EI hormigón debe colocarse por tongadas de 1,00 $\mathrm{m}$ de altura máxima, compactándose por vibración con aguja de 40 ó $50 \mathrm{~mm}$ de diámetro. La separación minima entre las armaduras y el poliestireno debe ser de 15 a $20 \mathrm{~mm}$ para facilitar la correcta ejecución del recubrimiento de ellas con el hormigón.

A la vista de los resultados obtenidos y dado que la estructura de los muros D-P II formada por pilares y vigas se considera tradicional, se decidió solamente abordar un conjunto simple de ensayos con muros sometidos a cargas de compresión en la nave de ensayos del Instituto Eduardo Torroja (figs. 2 у 3 ). 
Se fabricaron muros con pilares cada 0,60 ó $0,90 \mathrm{~m}$ que en unos casos eran de hormigón en masa y en otros estaban armados con $4 \varnothing 12$ y E $\varnothing 6 / 0,15$. Se utilizó un hormigón $\mathrm{H}-175$ y se proyectó sólo la primera capa del microhormigón del acabado para poder resistir el empuje del hormigón fresco de los pilares durante su construcción. Estas capas no llegaban a entrar en contacto con las vigas de los bordes superior e inferior de los muros a fin de que no pudiesen colaborar durante los ensayos.

La carga de rotura media obtenida en los ensayos de los muros con pilares de hormigón en masa fue de $27,5 \mathrm{t} /$ pilar, valor un $10 \%$ superior al obtenido mediante el cálculo aplicando la Norma EH-82 (1) y suponiendo una excentricidad nula de entrada de las cargas.

Algunios muros ensayados con pilares de hormigón armado tenian ciertos desplomes y faltas de planeidad de construcción. El valor medio de la carga de rotura obtenida con ellos fue de 34,0 t/pilar, valor un $18 \%$ superior al deducido también de los cálculos teóricos suponiendo que los defectos antes reseñados pudieran equivaler a una excentricidad de $2,0 \mathrm{~cm}$ de entrada de las cargas. Finalmente, el resto de los muros con pilares de hormigón armado sin defectos aparentes proporcionaron un valor medio de la carga de rotura de $54,5 \mathrm{t} / \mathrm{pilar}$, valor un $24 \%$ superior al obtenido teóricamente suponiendo una excentricidad nula de entrada de las cargas.

Todos los ensayos anteriores justificaron la posibilidad de hormigonar in situ los pilares de los muros D-P II y la aplicación de los criterios contenidos en la Norma EH-82 (1) para su cálculo.

\subsection{Muros D-P I}

En una primera fase se estudió el comportamiento de estos muros bajo cargas uniformes de compresión. Con tal fin, en el I. E. Torroja, en Geocisa y en el laboratorio de estructuras de la Escuela de Caminos se ensayaron un total de 33 muros de $1,20 \mathrm{~m}$ de ancho con un espesor de $0,13 \mathrm{~m}$ $(0,07 \mathrm{~m}$ de espesor del poliestireno) y con 2,70 y $3,10 \mathrm{~m}$ de altura. Las condiciones de sustentación durante los ensayos variaron estando en unos casos los muros apoyados en rótulas lineales en sus bordes más cortos mientras que en otros casos los muros tenian su borde inferior empotrado en zapatas de hormigón (figs. 4 y 5 ). Las cargas se aplicaron con excentricidades diferentes y por escalones, midiéndose en cada uno de ellos las flechas del muro en diferentes puntos y las deformaciones unitarias de las capas de micronormigón. La tabla 1 resume los valores medios de la carga de rotura obtenidos en cada serie de ensayos.

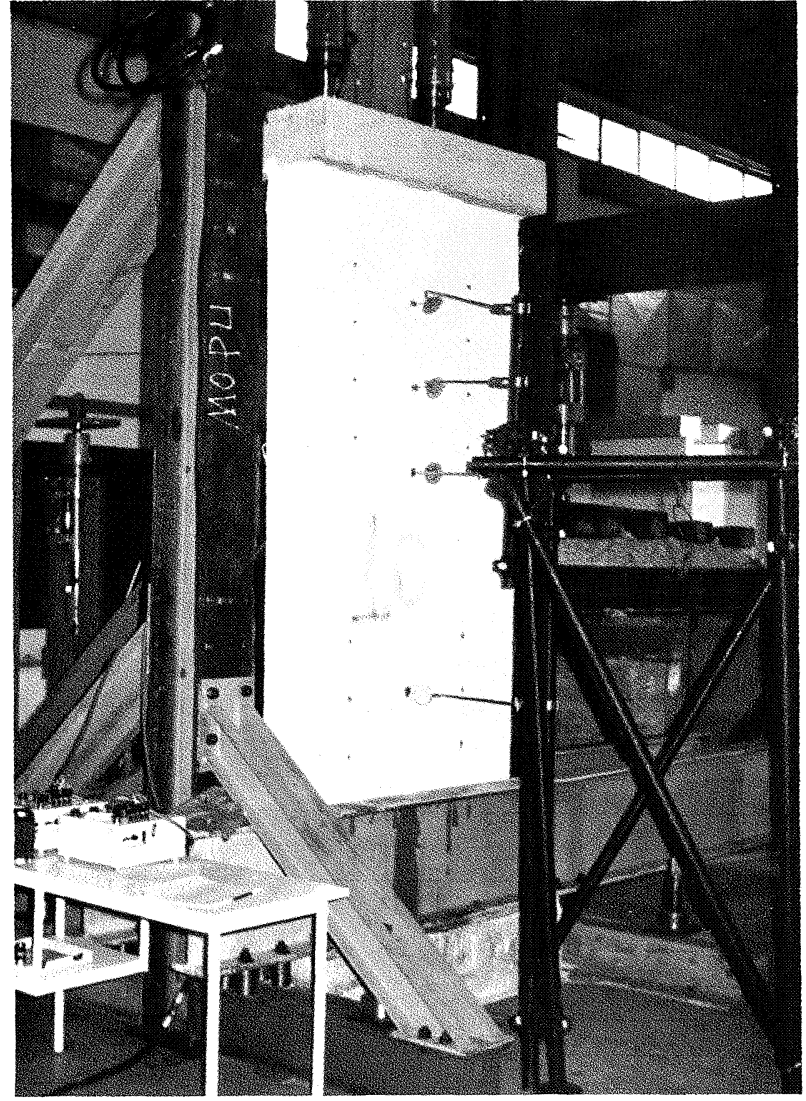

Fig. 4. - Ensayo a compresion de un muro D-P / unido a una zapata de hormigón.

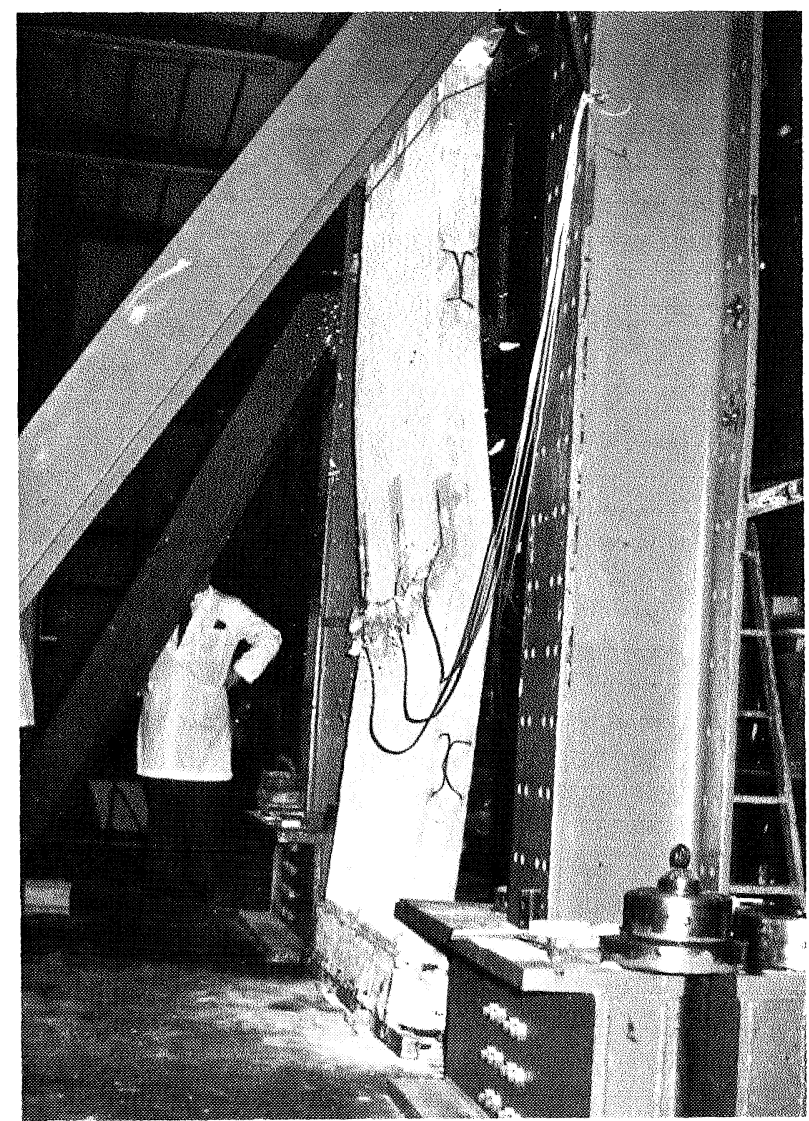

Fig. 5. - Rotura de un muro D-P / sometido a compresión excéntrica y apoyado sobre una rótula lineal. 
TABLA 1

Resultados de los ensayos de compresión de los muros D-P I

\begin{tabular}{|c|c|c|c|c|c|c|c|c|c|}
\hline SERIE & I & II & III & IV & V & VI & VII & VIII & IX \\
\hline ALTURA DEL MURO (m.) & 2,70 & 2,70 & 2,70 & 3,10 & 3,10 & 2,70 & 2,70 & 2,70 & 2,70 \\
$\begin{array}{c}\text { EXCENTRICIDAD EN EL } \\
\text { BORDE SUPERIOR (mm.) } \\
\text { EXCENTRICIDAD EN EL } \\
\text { APOYO INFERIOR (mm.) }\end{array}$ & 0 & 25 & 0 & 48 & 120 & 24 & 48 & 72 & 120 \\
$\begin{array}{c}\text { CARGA MEDIA } \\
\text { DE ROTURA (t.) }\end{array}$ & 73,4 & 65,0 & 62,1 & 29,2 & 7,6 & 53,0 & 46,8 & 37,6 & 17,0 \\
\hline
\end{tabular}

La situación de estos muros en los edificios construidos con este sistema corresponde a la de elementos verticales portantes de 2,70 m aproximadamente de altura libre entre plantas con momentos flectores variables y de signo contrario en cada extremo. Esta situación es similar a la reproducida en los ensayos VI al IX por lo que la capacidad portante admisible del muro D-P I ha podido deducirse directamente de los valores de rotura obtenidos. Sin embargo las condiciones impuestas en los muros de los ensayos I al V difieren de la situación real tanto en lo que respecta a la excentricidad constante como a la altura de los muros ensayados en las series IV y V. Este último aspecto no se ha tenido en cudenta quedándose asi del lado de la seguridad. En cuanto al tema de la excentricidad se ha asimilado de forma aproximada la situación del muro con excentricidad constante a lo largo de su altura a la de uno con excentricidad variable cuyo valor máximo es un $60 \%$ de la excentricidad constante. En todos los casos el valor de la capacidad portante se ha obtenido dividiendo el valor medio de la carga de rotura por un coeficiente igual a tres y se ha contrastado con los valores de las cargas que producian fisuración o deformaciones admisibles en los ensayos.

La figura 6 muestra la variación de la capacidad portante admisible de un muro de $2,70 \mathrm{~m}$ de altura libre, incorporado a un edificio intraslacional, en función de la excentricidad máxima de entrada de la carga. La zona de la curva para valores de la excentricidad superiores a $20 \mathrm{~cm}$ se ha obtenido mediante una interpolación entre los resultados de estos ensayos y los de los ensayos de flexión posteriormente reseñados.

Con estos ensayos también se estudió la influencia del número de conectores en el valor de la carga de rotura, no encontrándose ninguna cuando la separación vertical entre ellos variaba entre 0,10 y 0,60 , manteniéndose una separación horizontal de 0,30 m.

En una segunda fase se ensayó una serie de tres muros de 2,70 $\times 1,20 \times 0,13 \mathrm{~m}$ sometidos a cargas concentradas de compresión. Se aplicaron dos cargas a 0,60 m de distancia entre si a través de unas placas metálicas de $130 \times 130$ $\mathrm{mm}$, en contacto con el borde superior del muro (fig. 7). La rotura se produjo por aplastamiento del microhormigón bajo una de las placas para una carga media por gato de 22,9 t y los resultados pusieron de manifiesto que los esfuerzos se distribuyen uniformemente en el ancho del muro a partir de una distancia de $0,80 \mathrm{~m}$ del borde superior.

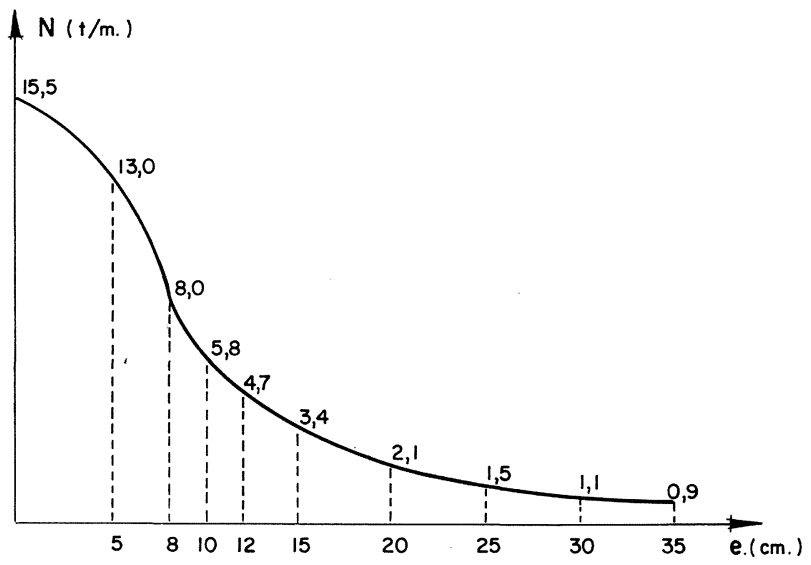

Fig. 6. - Relacion entre la carga vertical admisible "N" y la excentricidad maxima "e" en miros $D-P I$.

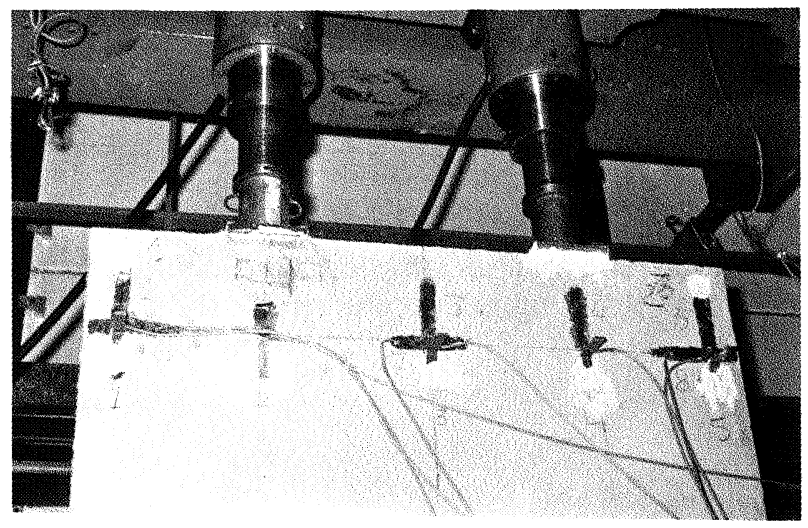

Fig. 7. - Rotura de un muro D-P I bajo la actuacion de dos cargas concentradas.

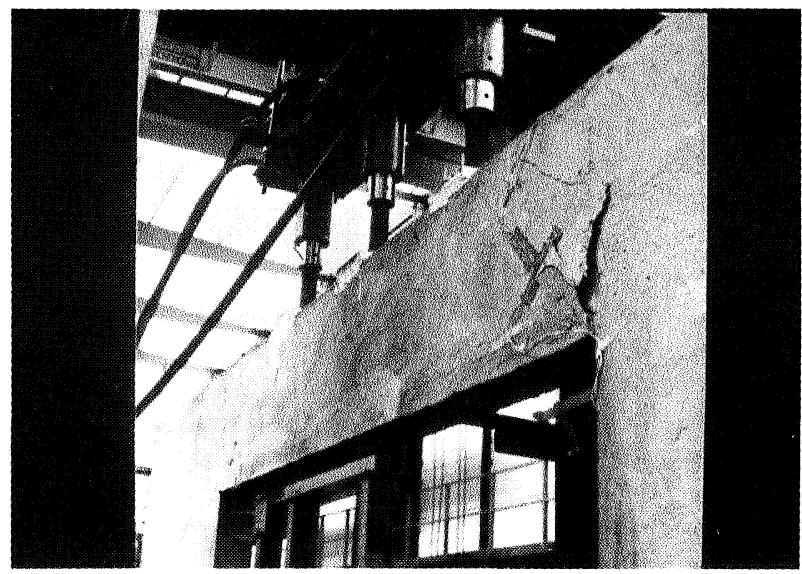

Fig. 8. - Rotura de la viga dintel de un hueco en un muro D-P I. 
En una tercera fase se estudió la capacidad resistente de las vigas dintel de los huecos de puertas y ventanas en los muros D-P I. Se ensayó una serie de tres muros iguales con un hueco de ventana de $2,00 \mathrm{~m}$ de longitud y una viga dintel de $0,40 \mathrm{~m}$ de canto (fig. 8). Las cargas, que se aplicaron sobre la viga dintel, produjeron la rotura por fallo a cortante y a momento negativo de las secciones de unión entre la viga y el muro, para valores de la carga uniforme equivalente de $7,2 \mathrm{t} / \mathrm{m}$.

El sistema constructivo prevé la colocación de muros portantes en dos direcciones para rigidi-

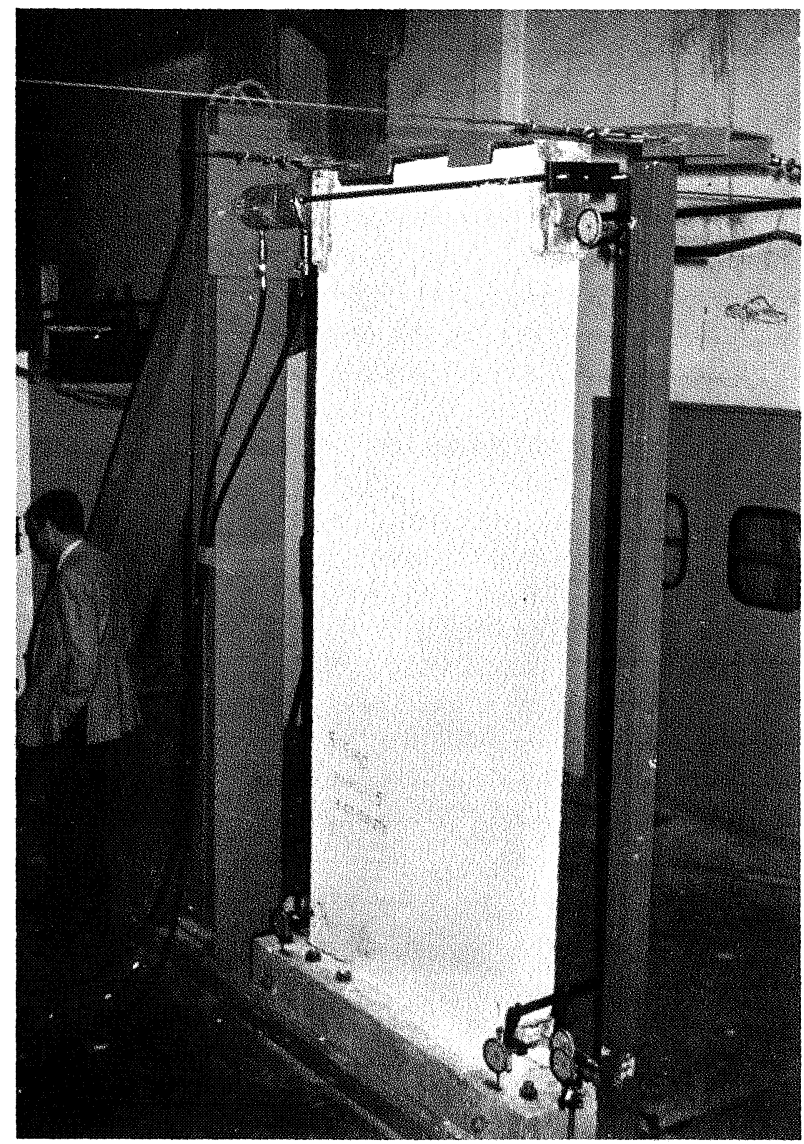

Fig. 9. - Ensayo a carga horizontal de un muro D-P I unido a una zapata de hormigón.

\section{TABLA 2}

\section{Resultados de los ensayos de muros D-P I} sometidos a carga horizontal

\begin{tabular}{|c|c|c|}
\hline DIMENSION DEL MURO $(\mathrm{m})$ & UNION A ZAPATA & CARGA DE ROTURA $(\mathrm{t} / \mathrm{m})$. \\
\hline $1,20 \times 2,70$ & PLACA DE ANCLAJE & 0,94 \\
$1,20 \times 2,70$ & $\emptyset 6 / 0,30$ & 2,17 \\
$2,40 \times 2,70$ & PLACA DE ANCLANE & 1,55 \\
$2,40 \times 2,70$ & $\emptyset 6 / 0,30$ & 2,99 \\
\hline
\end{tabular}

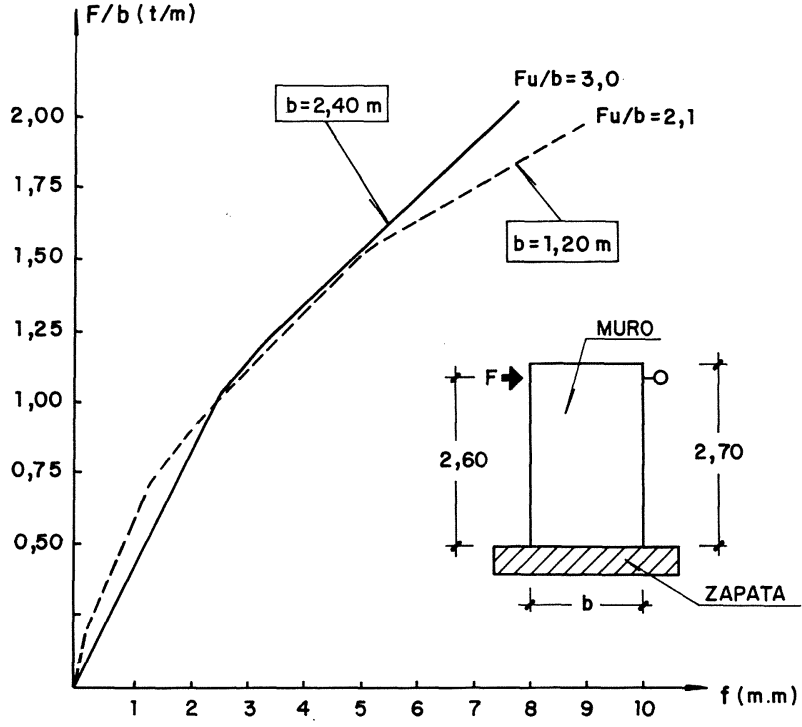

Fig. 10. - Relación entre la carga horizontal por unidad de longitud "F/b" y el valor medio de la flecha "f» obtenida en los ensayos de muros $D-P I$.

zar los edificios frente a las acciones horizontales del viento y del sismo por lo que se estudió, en una cuarta fase, el comportamiento resistente y la ductilidad de los muros ante estas solicitaciones. Se ensayaron un total de 12 muros con $2,70 \mathrm{~m}$ de altura y 1,20 y $2,40 \mathrm{~m}$ de longitud, conectados a unas zapatas de hormigón mediante armaduras $\varnothing 6 / 0,30$ ó por medio de placas de anclaje cada 1,20 m (fig. 9). En cada ensayo se hicieron varios ciclos de carga en uno y otro sentido hasta un valor considerado de servicio, y tal que producia fisuración de separación entre el muro y la zapata en el extremo que actuaba la carga. A continuación se llevó el muro hasta su rotura, actuando en uno de los sentidos. En la tabla 2 se resumen los valores medios de los resultados obtenidos en las cuatro series de muros ensayados.

En la fig. 10 se representan las curvas que relacionan los valores medios de las fuerzas aplicadas por unidad de longitud y las flechas en coronación para el último ciclo de carga de los muros unidos a las zapatas mediante armaduras. La rotura se produjo siempre por fallo de la adherencia con el microhormigón de los redondos de anclaje, para tensiones de tracción en el acero de $3.200 \mathrm{kp} / \mathrm{cm}^{2}$, sin producirse la rotura de los muros que tenian pequeñas fisuras a flexión y cortante. Las tensiones tangenciales medias en las capas del microhormigón en el momento de la rotura fueron de 4,2 y $6,0 \mathrm{kp} / \mathrm{cm}^{2}$ para los muros de 1,20 y $2,40 \mathrm{~m}$ de largo respectivamente. Es de hacer notar que los ensayos asi planteados han supuesto una situación de los muros más desfavorable que la real, ya que ni se ha contado con el efecto favorable de las cargas verticales ni con la colaboración de los muros perpendiculares unidos a ellos que, en todo caso, existen en los edificios construidos con este sistema. 


\subsection{Forjados D-P I}

La utilización de elementos D-P I para forjados de cubierta y para fachadas de edificios ha requerido estudiar su comportamiento ante la acción de las cargas actuando perpendicularmente a su plano medio. Por ello se plantearon un conjunto de ensayos, que se realizaron en el I. E. Torroja y en Geocisa, para estudiar el comportamiento a flexión de forjados de $0,13 \mathrm{~m}$ de canto y $1,20 \mathrm{~m}$ de ancho con uno o dos vanos (fig. 11). Algunos de los forjados de un vano fueron reforzados en su cara inferior con redondos $\varnothing 6 / 0,20$. Los forjados de dos vanos se construyeron con dos paneles unidos sobre el apoyo central mediante el solapo de sus mallas.

Las cargas se aplicaron de forma uniforme o en varias secciones y se aumentaron progresivamente hasta la situación de rotura que se produjo por tracción en la cara inferior de los forjados de un vano sin refuerzos y por cortante en el resto de los casos. Durante la aplicación de las cargas se midieron las flechas, las deformaciones en las armaduras de refuerzo y se controló la fisuración.

La tabla 3 resume algunos de los resultados obtenidos y la fig. 12 representa la relación entre

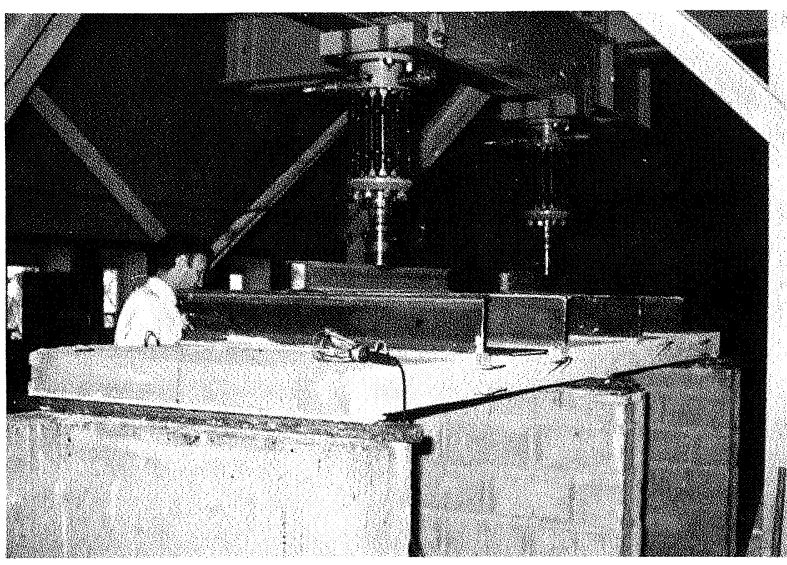

Fig. 11. - Ensayo de un forjado D-P / de dos vanos.

\section{TABLA 3}

Valores medios de los resultados de los ensayos de flexión de forjados D-P I

\begin{tabular}{|c|c|c|c|c|c|}
\hline \multirow{2}{*}{ SERIE } & \multirow{2}{*}{$\begin{array}{c}\text { LONGITUD DEL } \\
\text { VANO (m.) }\end{array}$} & \multicolumn{2}{|c|}{ FISURACION $(0,1 \mathrm{~mm})}$. & \multicolumn{2}{c|}{ SITUACION DE ROTURA } \\
\cline { 3 - 6 } & $\begin{array}{c}\text { CARGA } \\
\mathrm{k} / \mathrm{m} \text { ? }\end{array}$ & $\begin{array}{c}\text { MOMENTO } \\
(\mathrm{m} \times \mathrm{t} / \mathrm{m} .)\end{array}$ & $\begin{array}{c}\text { CARGA } \\
\mathrm{K} / \mathrm{m}^{2}\end{array}$ & $\begin{array}{c}\text { MOMENTO } \\
(\mathrm{m} \times \mathrm{ft} / \mathrm{m} \text {.) }\end{array}$ \\
\hline 1 & 2,95 & 239 & 0,26 & 620 & 0,68 \\
\hline 2 & $1,95(*)$ & & 0,27 & & 0,72 \\
\hline 3 & 3,55 & 177 & 0,28 & 470 & 0,74 \\
\hline 4 & $3,55(* *)$ & 247 & 0,39 & 540 & 0,85 \\
\hline 5 & $3,55(* * *)$ & & & 745 & 1,18 \\
\hline
\end{tabular}

(*) DOS VANOS

(**) ARM. INF DE REF $06 / 0,20$

(***) BORDES MACIZADOS Y ARM. INF. DE REF. $\varnothing 6 / 0,20$

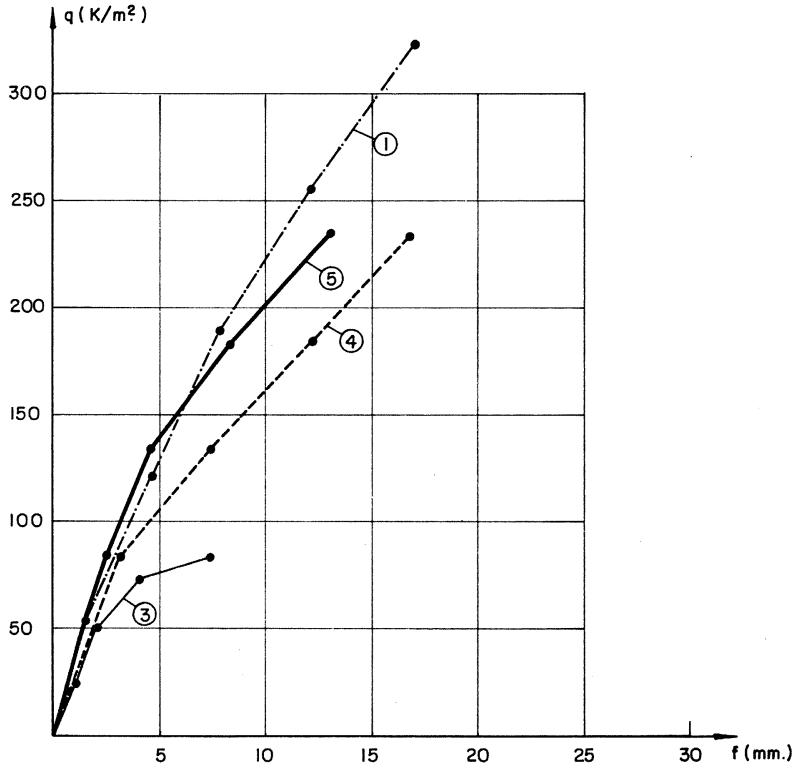

Fig. 12. - Relación entre la carga y el valor medio de la flecha en centro de vano obtenida en los ensayos de forjados $D-P I$.

las cargas aplicadas (excluido el peso propio) y los valores medios de las flechas en centro de vano de los forjados ensayados.

Estos ensayos, además de proporcionar los valores de las solicitaciones en las situaciones de fisuración y de rotura, han confirmado la posibilidad de unir diferentes paneles mediante el solapo de sus mallas \# $\varnothing 3 / 0,10$ con una longitud minima de solapo de 0,20 $\mathrm{m}$. También han demostrado la viabilidad del refuerzo con armaduras $\varnothing 6$ embebidas en las capas de microhormigón en las que se han llegado a medir durante los ensayos deformaciones correspondientes a tensiones de $4.500 \mathrm{~kg} / \mathrm{cm}^{2}$, siendo las armaduras del tipo AEH 500.

\section{ENSAYOS CON ELEMENTOS COMPUESTOS}

\subsection{Uniones entre muros D-P I y forjados}

Se estudió el comportamiento de las uniones entre muros D-P I y forjados Cádiz o D-P I mediante la realización de ensayos en el laboratorio Geocisa con ocho elementos de $1,20 \mathrm{~m}$ de ancho y $1,60 \mathrm{~m}$ de altura que reproducian cuatro tipologias de uniones de ambos tipos de forjados con muros exteriores o muros interiores (Figs. 13 y 14).

En los ensayos se aplicaron cargas centradas en la parte superior de los muros y directamente sobre los forjados a distintas distancias de los muros, con el fin de estudiar el comportamiento de las uniones bajo distintas combinaciones de cargas y excentricidades. Los muros se apoyaron en su borde inferior y tenian impedido su desplazamiento horizontal en sus bordes superior e inferior. 


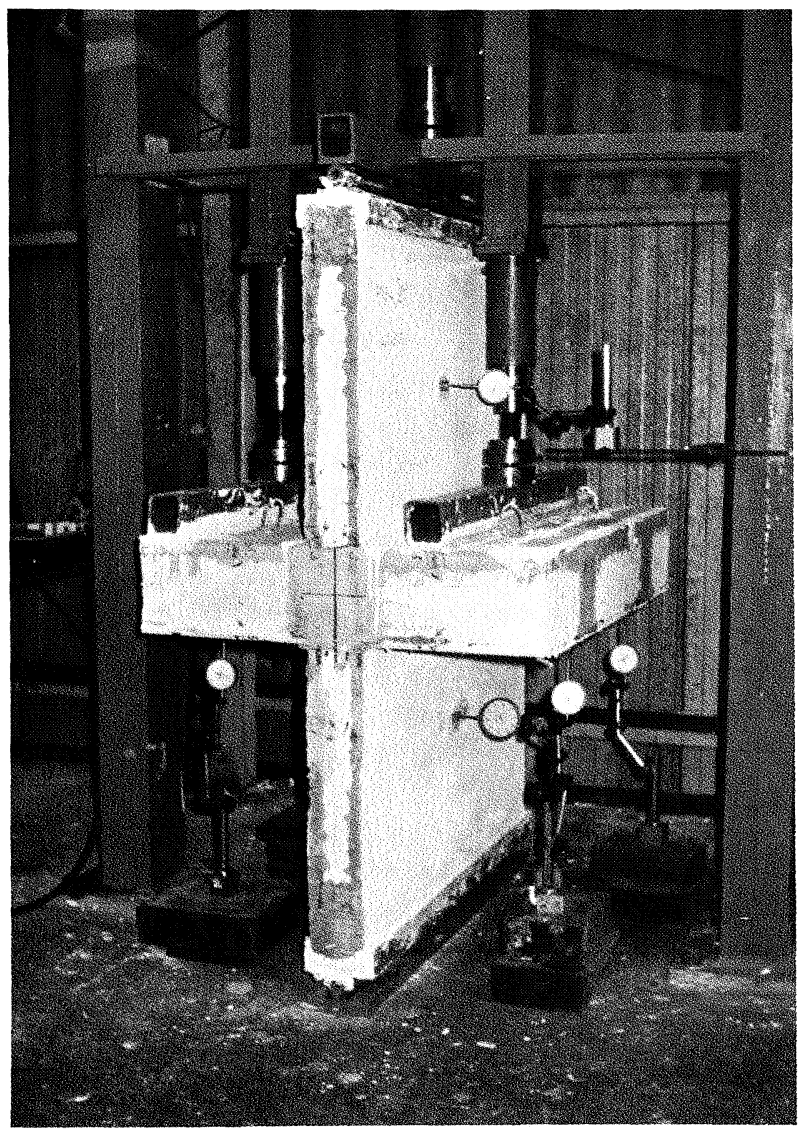

Fig. 13. - Ensayo de una unión entre forjado Cadiz y muro interior D-P I.

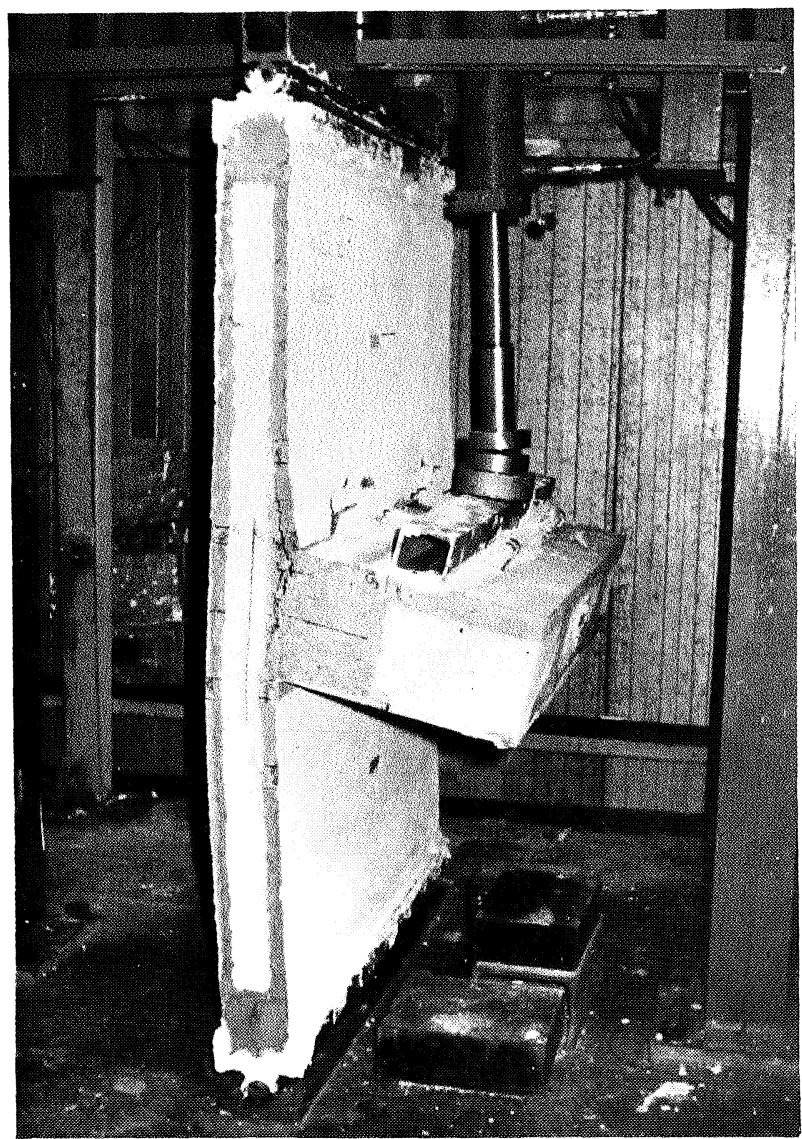

Fig. 14. - Rotura de la unión eiisáyaúua eñtie forjado Cadiz y muro exterior $D-P I$

\section{TABLA 4}

\section{Resultados de los ensayos de uniones entre} muros D-P I y forjados

\begin{tabular}{|c|c|c|c|c|}
\hline \multirow{2}{*}{ ENSAYO } & \multicolumn{2}{|c|}{$\begin{array}{l}\text { MUROS D.-P.I. Y FORJADO CADIZ } \\
\text { DE } 0,20 \mathrm{~m} \text {. DE CANTO }\end{array}$} & \multicolumn{2}{|c|}{ MUROS Y FORJADOS D.-P.I. } \\
\hline & $\begin{array}{c}\text { CARGA DE ROTURA } \\
(t .)\end{array}$ & $\begin{array}{l}\text { EXCENTRICIDAD } \\
\text { DE LA CARGA(m) }\end{array}$ & $\begin{array}{c}\text { CARGA DE ROTURA } \\
\text { (1.) }\end{array}$ & $\begin{array}{l}\text { EXCENTRICIDAD } \\
\text { DE LA CARGA(m) }\end{array}$ \\
\hline MURO INTERIOR & 10,20 & 0,20 & 1,20 & 0,30 \\
\hline MURO INTERIOR & 9,80 & 0,25 & 2,00 & 0,20 \\
\hline MURO EXTERIOR & 6,25 & 0,24 & 2,35 & 0,17 \\
\hline MURO EXTERIOR & 6,30 & 0,24 & 3,35 & 0 \\
\hline
\end{tabular}

En cada caso se cargaron, en primer lugar, los forjados hasta el doble de la carga de servicio estimada, aumentándose la carga en los muros hasta la de servicio correspondiente a una planta, sin detectarse ninguna anomalia. Posteriormente se disminuyó la carga en los muros hasta un minimo $(\sim 0,5 \mathrm{t})$ que asegurase la estabilidad del conjunto, aumentándose la carga en los forjados hasta producir la rotura.

En la tabla 4 se resumen algunos de los resultados obtenidos. En los ensayos con forjados Cádiz la rotura se produjo por la unión del muro superior al forjado en el caso de los muros interiores y por la unión del forjado al muro en el caso de los ensayos con muros exteriores. En los ensayos con forjados D-P I la rotura se produjo siempre por fallo de la unión del forjado al muro.

\subsection{Elementos formados por muros y cubierta D-P I}

Se llevó a cabo una prueba de carga hasta la rotura de un modelo que reproducia a escala real la tipología estructural de un edificio de una planta construido en Argel, con lo que se pudo verificar el comportamiento de una estructura compuesta por muros y forjados D-P I unidos entre si con el tipo de uniones anteriormente ensayadas.

La estructura vertical estaba formada por tres muros de $0,14 \mathrm{~m}$ de espesor y $2,50 \mathrm{~m}$ de altura que en planta formaban una $U$ con un hueco de ventana de 2,00 m de longitud en el muro central. El forjado tenía luces de 3,10 y 3,65 en cada dirección con voladizos de $0,55 \mathrm{~m}$ y se construyó con paneles D-P I terminados por su cara inferior con 4,5 cm de microhormigón armado y por su cara superior con $6,5 \mathrm{~cm}$ de espesor de hormigón de $175 \mathrm{kp} / \mathrm{cm}^{2}$ de resistencia característica.

Se realizaron varios ciclos de carga-descarga del forjado llegando hasta $530 \mathrm{~kg} / \mathrm{m}^{2}$, sin detectarse problema alguno. Se aumentó la carga hasta $890 \mathrm{~kg} / \mathrm{m}^{2}$, apareciendo fisuras de $0,2 \mathrm{~mm}$. Se mantuvo la carga 11 dias para conocer el comportamiento del elemento bajo carga. Con el fin de alcanzar la situación de rotura, se cargó el 


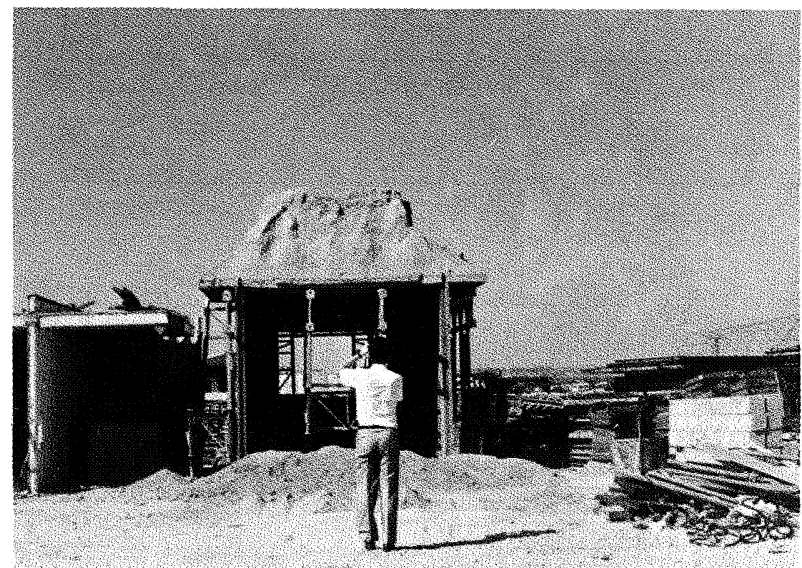

Fig. 15. - Prueba de carga de una estructura con muros y forjado D-P I.

forjado con arena contenida en un recinto metálico formado por cuatro encofrados. La rotura se produjo para una carga de arena de $1.550 \mathrm{~kg} / \mathrm{m}^{2}$, si bien este valor es sólo orientativo de la carga realmente aplicada en el forjado debido al sistema empleado (fig. 15).

\subsection{Elementos formados por muros D-P I y forjados Cádiz}

Con anterioridad a los ensayos realizados con los elementos aislados se llevó a cabo la construcción y el ensayo de tres módulos iguales de $2,40 \mathrm{~m}$ de ancho, formados cada uno por dos muros D-P I de 2,65 m de altura y un forjado Cádiz de $0,19 \mathrm{~m}$ de canto con un vano y un voladizo de 4,80 y 2,00 m de luz respectivamente. Se pretendia entonces experimentar con el sistema D-P I estudiando los aspectos constructivos y su comportamiento estructural. Estos módulos se ensayaron aplicando cargas uniformemente distribuidas en el forjado y cargas lineales directa- mente sobre la parte superior de los muros, simulando en este segundo caso la posible existencia de un forjado superior (fig. 16). Se llevaron a cabo diferentes ciclos de carga dándose los ensayos por terminados cuando el valor de las cargas en forjados y muros eran del orden del doble de las de servicio, sin que se hubiera producido el colapso de ningún elemento.

No fue posible llegar a la situación de rotura al no contarse con más medios para aumentar las cargas, ya que estos ensayos se realizaron en campo y las cargas se introdujeron mediante piscinas de agua, bloques de hormigón y elementos metálicos. Además, la construcción de estos módulos se realizó con la tecnología y los conocimientos de aquel momento, habiendo utilizado en los muros D-P I paneles de poliestireno defectuosos y proyectándose un microhormigón de composición diferente al empleado en los ensayos posteriores. Por todo ello se decidió plantear una nueva fase de ensayos en el laboratorio de Geocisa con posterioridad a los efectuados con los elementos aislados del sistema constructivo, que permitió realizar diferentes ciclos de carga sobre modelos con forjados de cantos y luces diferentes, llegando en todos los casos hasta la situación de rotura.

Con tal fin se construyeron dos series de tres modelos iguales cada una, de 1,20 m de ancho, que reproducian el vano extremo de la planta superior de edificios construidos con muros D-P I y forjados Cádiz para luces de $3,50 \mathrm{~m}$ y $5,00 \mathrm{~m}$ y cantos de forjados de $0,14 \mathrm{~m}$ y $0,20 \mathrm{~m}$ respectivamente. Los muros, de $1,30 \mathrm{~m}$ de altura, se apoyaron durante los ensayos en rótulas lineales con lo que reprodujeron las condiciones estructurales de éstos, si se admite que en la realidad el punto de momento nulo se sitúa en una sección próxima a la media altura entre las plantas (fig. 17).

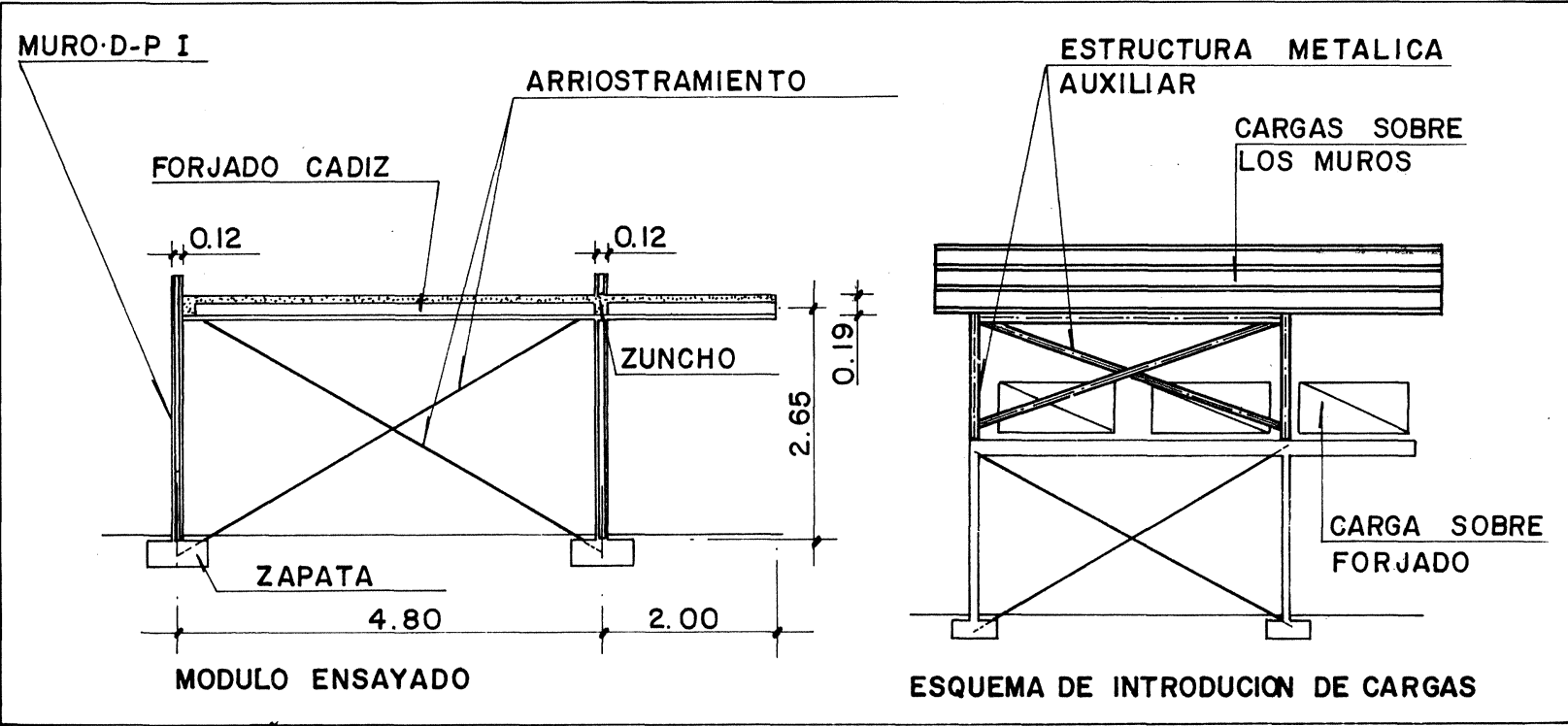

Fig. 16. - Prueba de carga de estructuras con muros D-P I y forjado Cádiz. 
Las uniones entre muros y forjados se realizaron, de acuerdo a lo establecido en el sistema constructivo, mediante vigas zuncho de hormigón armado centradas sobre los muros interiores y excéntricas sobre los muros exteriores. Los modelos se arriostraron longitudinalmente por medio de tirantes, ya que los edificios construidos con este sistema tienen garantizada su intraslacionalidad por la disposición de muros en dos direcciones.

Mediante la utilización de un pórtico se aplicaron cargas lineales en el vano (a tercios de la luz) y/o en el voladizo. Se efectuaron varios ciclos de cargas para valores inferiores a los de servicio y posteriormente se incrementaron hasta alcanzar la situación de rotura.

Con estos ensayos se pudo estudiar por una parte el comportamiento de las uniones entre forjados Cádiz y muros D-P I (interior y exterior) cuando la excentricidad de entrada de las cargas en estos últimos no era un dato de partida del ensayo sino que dependia de la rigidez relativa entre muros y forjados. Por otra parte se pudo también estudiar el comportamiento del conjunto formado por muros y forjados de luces y cantos representativos de los utilizados en los edificios construidos con este sistema.

Durante los ensayos se midieron las flechas en el forjado, los giros en la unión del forjado con el muro extremo y las deformaciones unitarias de las capas de microhormigón de los muros y las de algunas armaduras de los muros y forjados. La tabla 5 resume los valores de las cargas en la situación de rotura.

En los modelos con forjados de $0,14 \mathrm{~m}$ de canto se llegaba a la rotura del voladizo antes de producirse el colapso global de la estructura por lo que se decidió mantener la carga aplicada en él en un cierto rango de valores mientras que se aumentaban las cargas en el vano. La rotura del conjunto de la estructura se produjo en todos los ensayos por el fallo casi simultáneo del forjado en su unión con el muro interior y bajo una de las cargas y del muro extremo (fig. 18).

Estos ensayos han puesto de manifiesto el correcto comportamiento de esta tipologia estructural alcanzándose valores de las solicitaciones en sus elementos del orden de tres veces mayores que las producidas por las cargas de servicio.

\section{CONCLUSIONES}

La experimentación aqui resumida y los estudios llevados a cabo han permitido establecer los criterios para el diseño y el cálculo de los edificios construidos con el sistema Dragados-Plastbau, de una o dos plantas con muros portantes D-P I y hasta cinco plantas con muros portantes D-P II.

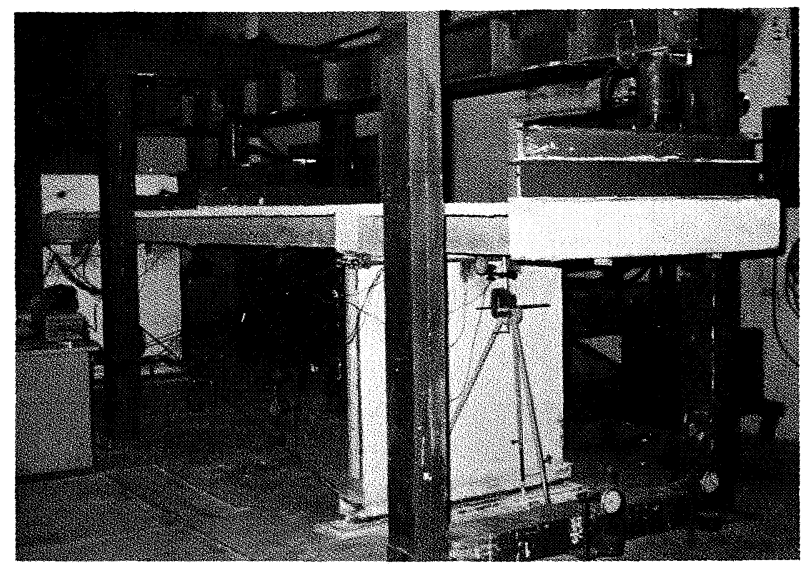

Fig. 17. - Ensayo de una estructura formada por dos muros D-P I y un forjado Cádiz.

TABLA 5

Cargas en la situación de rotura de las estructuras ensayadas formadas por muros D-P I y forjados Cádiz

\begin{tabular}{|c|c|c|c|}
\hline \multirow{2}{*}{ FOR JADO } & \multirow{2}{*}{ ENSAYO } & \multicolumn{2}{|c|}{ CARGAS (t.) } \\
\cline { 3 - 4 } & & VANO & VOL ADIZO \\
\hline $\mathrm{L}=3,50 \mathrm{~m}$. & 1 & 3,58 & 2,76 \\
$\mathrm{~h}=0,14 \mathrm{~m}$. & 2 & 3,65 & 1,40 \\
$\mathrm{~L}=5,00 \mathrm{~m}$. & 3 & 3,16 & 2,26 \\
$\mathrm{~h}=0,20 \mathrm{~m}$. & 2 & 3,39 & 3,39 \\
\hline & & 3,62 & 3,62 \\
\hline
\end{tabular}

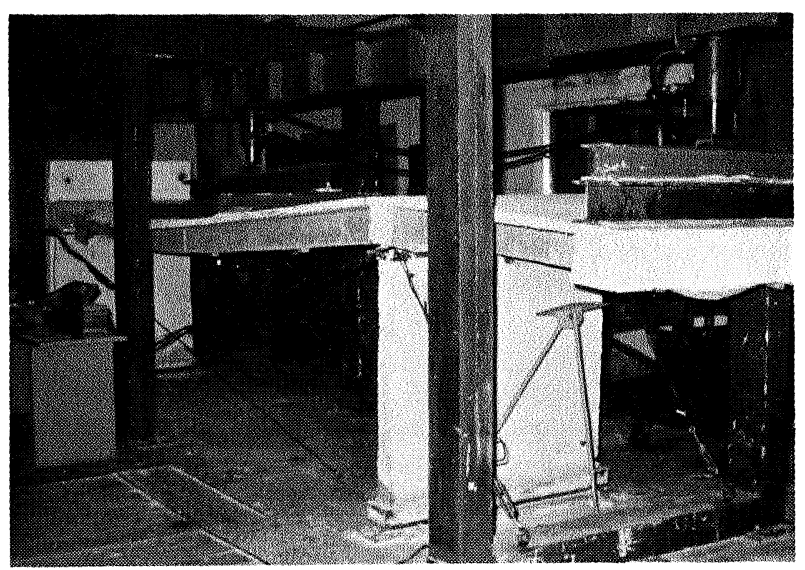

Fig. 18. - Rotura de la estructura ensayada formada por dos muros D-P I y un forjado Cádiz. 
34

Informes de la Construcción, Vol. 38, n.o 383, agosto-septiembre, 1986

\subsection{Edificios con muros D-P I}

La capacidad portante admisible de los elementos D-P I se ha fijado a partir de los resultados obtenidos en los ensayos, con un coeficiente de seguridad de 3 respecto a la situación de rotura y de manera que las deformaciones y la fisuración resulten compatibles con el uso de estos elementos (4).

La figura 6 representa el valor admisible de las cargas verticales en un muro portante, en función de la excentricidad máxima de entrada de las cargas, cuando éstas se aplican de forma uniforme. Si las cargas son concentradas y actúan sobre el muro de forma centrada y con una placa de reparto no menor de 0,13 $\times 0,13 \mathrm{~m}$, el valor admisible de éstas es de 7,5 t. Si el muro tiene huecos para puertas o ventanas y las cargas que gravitan sobre dicho hueco tienen que ser resistidas por su dintel, no podrán sobrepasar el valor de $2,6 \mathrm{t} / \mathrm{m}$ si el hueco tiene una longitud máxima de $2,0 \mathrm{~m}$ con $0,40 \mathrm{~m}$ de canto mínimo de la viga dintel.

Las tensiones tangenciales en las capas de microhormigón de los muros D-P I sometidos a acciones horizontales no sobrepasarán el valor de $3,0 \mathrm{kp} / \mathrm{cm}^{2}$ y su comprobación a flexión puede realizarse según la teoría de los estados límites siempre que la tensión de cálculo de las armaduras de unión de los muros entre sí o con la cimentación no supere el valor de $3.200 \mathrm{kp} / \mathrm{cm}^{2}$.

Los elementos D-P I utilizados como cubiertas o cerramientos podrán resistir la acción de cargas perpendiculares a su plano medio siempre que el momento flector sea menor que $0,39 \mathrm{mt} / \mathrm{m}$ ó 0,24 $\mathrm{mt} / \mathrm{m}$ para elementos con o sin armadura de refuerzo $\varnothing 6 / 0,20$ en la cara traccionada y el cortante sea inferior a $0,5 \mathrm{t} / \mathrm{m}$.

El cálculo de las solicitaciones en los elementos de edificios sometidos a cargas gravitatorias y construidos con muros y cubiertas D-P I se lleva a cabo mediante un cálculo convencional considerando las uniones entre muros y forjados como uniones rígidas. Las solicitaciones resultantes se contrastan con los valores admisibles indicados anteriormente.

Los forjados Cádiz de los edificios construidos con muros D-P I se calculan bajo la acción de las cargas gravitatorias, según lo establecido en la Instrucción EH-82 (1) considerándolos como elementos continuos articulados sobre los muros. La comprobación de los muros se realiza calculando las cargas que sobre ellos gravitan, deducidas de las reacciones de los forjados y contrastándolas con los valores admisibles indicados en la tabla 6 para valores $L_{1}$ y $L_{2}$ de las luces de los forjados adyacentes inferiores a 6,0 m.
TABLA 6

Valor de la carga admisible $(\mathrm{t} / \mathrm{m})$ de los muros D-P I de edificios con una o dos plantas

\begin{tabular}{|l|c|c|c|c|c|}
\hline \multirow{2}{*}{ MURO } & \multicolumn{2}{|c|}{ EXTREMO } & \multicolumn{3}{c|}{ IN TERIOR } \\
\cline { 2 - 6 } & $\begin{array}{l}\text { FORJADO CON } \\
\text { UN VANO }\end{array}$ & $\begin{array}{l}\text { FOR JADO CON } \\
\text { VARIOS VANOS }\end{array}$ & $L_{1} \geqslant 2 L_{2}$ & $L_{1}=1,5 L_{2}$ & $L_{1}=L_{2}$ \\
\hline $\begin{array}{l}\text { PLANTA } \\
\text { SUPERIOR }\end{array}$ & $0,9-1,6^{*}$ & $1,1-1,9^{*}$ & 4,7 & 5,8 & 13,0 \\
\hline $\begin{array}{l}\text { PLANTA } \\
\text { INFERIOR }\end{array}$ & 5,8 & 5,8 & 13,0 & 13,0 & 13,0 \\
\hline
\end{tabular}

* Muro D-P I con armadura $\varnothing 6 / 20$ de refuerzo en la cara exterior.

Los edificios construidos con este sistema tienen muros situados en dos direcciones. Las tensiones tangenciales en las capas de microhormigón de estos muros debidas a la acción del viento (6) o del sismo (Norma Sísmica PDS-1; construcciones tipo $C$ [7]) no superarán los 3,0 ó 4,5 $\mathrm{kp} / \mathrm{cm}^{2}$, respectivamente, comprobándose en todo caso la seguridad al vuelco del edificio.

\subsection{Edificios con muros D-P II}

El cálculo de los edificios construidos con muros D-P II se realiza de acuerdo a la teoría general de estructuras y según lo establecido en la norma EH-82 (1). Se disponen muros en ambas direcciones para hacer frente a las acciones horizontales, pudiendo contar en algunos casos con la capacidad arriostrante de las capas de acabado de los muros sin pilares.

Si los pilares son de hormigón en masa, la unión de los forjados a ellos se considera como una articulación y el modelo adoptado para obtener la excentricidad de entrada de las cargas en los muros es el de un reparto trapecial de las tensiones obtenido a partir de una distribución triangular de profundidad igual al canto del forjado.

En zonas sísmicas de grado VIII o superior se disponen muros en dos direcciones con pilares de hormigón armado y la construcción se considera del tipo $C$ (7). En el resto de las zonas puede contarse con la capacidad arriostrante de las capas de acabado interiores de los muros y en este caso las construcciones se consideran del tipo $B(7)$ y la tensión tangencial admisible es de $1,0 \mathrm{kp} / \mathrm{cm}^{2}$.

Actualmente se está finalizando un programa de ensayos en el laboratorio de Estructuras de la Escuela de Caminos para determinar la capacidad portante de los muros D-P II contando con la colaboración resistente de las capas de microhormigón. 


\section{BIBLIOGRAFIA}

1. Comisión Permanente del Hormigón: «Instrucción para el proyecto y la ejecución de obras de hormigón en masa o armado». MOPU, Madrid, 1982.

2. A.S.T.M.: "Standard Methods of conducting strength test of panels for building construction", ASTM, E72-80.

3. A.S.T.M.: "Standard Method of Static load-test for shear resistance of framed walls for buildings", ASTM E 564-76.

4. International Conference of Building Officials Research Commitee: «Acceptance criteria for sandwich panels», California, April 1977.

5. LUGEZ, J.: "Recommendations pour les essais de joints horizontaux entre murs porteurs et plan- chers", Materials and Structures, vol. 13, n.0 78, 1980.

6. M.O.P.U.: “Acciones en la edificación», NBE-MV101, Madrid, 1962.

7. "Norma Sismorresistente». P.D.S.-1. Parte A. Normativa, Madrid, 1974.

8. QUEREDA, J.; ARTEAGA, A.; FLOREZ, J.; RODRIGUEZ, J: «Aspectos estructurales del sistema constructivo Dragados-Plastabau", XXIII, Jornadas Sudamericanas de Ingenieria Estructural, Colloquia 85, Memorias B, Tomo I, pp. 140-157, Buenos Aires, 1985.

9. QUEREDA, J.; FLOREZ, J.; RODRIGUEZ, J.: "Structural behaviour of Dragados-Plastbau building system», CIB 86, Advancing Building Technology, Translating Research into Practice, vol. 6, pp. 2594-2601, Washington, 1986.

\section{publicaciones del I.E.T.c.c.}

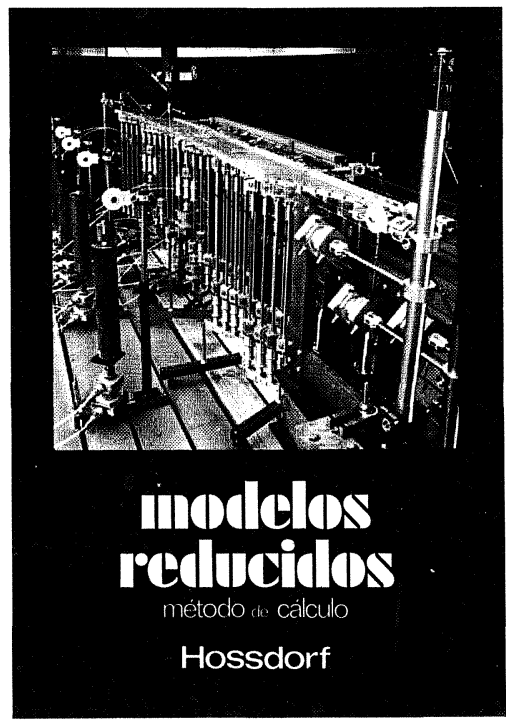

Modelos reducidos. Método de cálculo

H. Hossdorf, Ingeniero Civil

La técnica de los ensayos en modelos reducidos de estructuras sufre hoy dia una decisiva metamorfosis. Hasta hace poco era un medio más bien de artesanasta que no siempre era tomado en serio por los nia, que no sierizantes para comprender el comporta miento resistente de las estructuras complejas y a que se acudió las más de las veces, como a un último remedio debido a sus indiscutibles insuficiencias. Sin embargo, en poco tiempo y gracias a su conexión con los ordenadores digitales, se ha trans formado en un instrumento cientificamente valioso que no puede quedar a un lado en la práctica diaria del Ingeniero Proyectista.

Un volumen encuadernado en cartoné plastificado con lomo de tela, de $17 \times 24 \mathrm{~cm}$, compuesto de 250 páginas, 158 figuras $y$ fotografias.

Precios: 1.800 ptas.; \$ USA 26.00

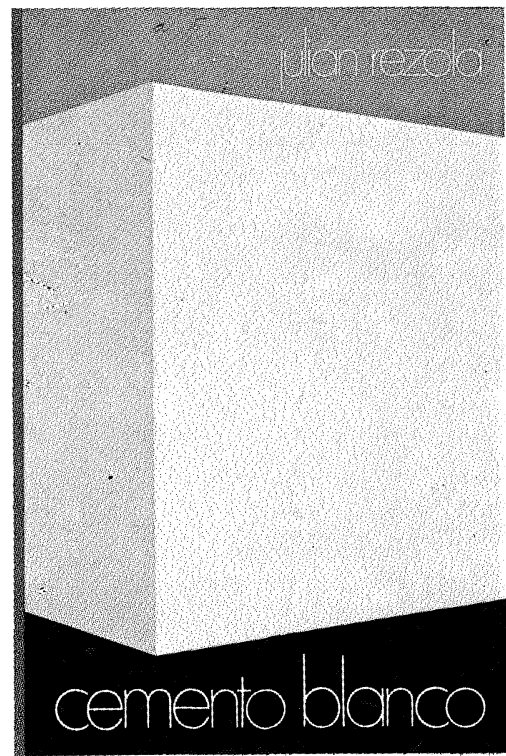

Cemento blanco

Julián Rezola

Ingeniero Quimico Dipl. I. O. S.

Sabido es que existe una extensa y documentada bibliografía sobre el cemento gris: en cambio, no puede decirse lo mismo acerca del cemento portland blanco, ya que los escritos existentes se refieren tan sólo a algunas peculiaridades que le distinguen de aquél.

El autor nos ofrece sus profundos conocimiento su larga experiencia tanto en laboratorio como
en fabricación.

La parte descriptiva del libro se complementa con gráficos, diagramas y fotografias de gran utilidad, destinados a conseguir la aplicación apropiada de este aglomerante.

Un volumen encuadernado en cartoné policerado, de $17,4 \times 24,3 \mathrm{~cm}$, compuesto de 395 páginas

Precios: España, 1.700 ptas.; extranjero, \$ 24.

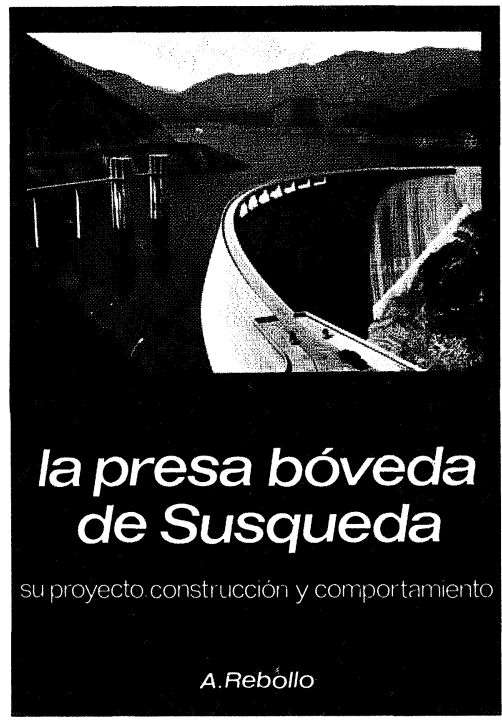

La presa bóveda de Susqueda

A. Rebollo,

Dr. Ingeniero de Caminos

El esfuerzo del constructor de presas se sitúa, por su pretensión de perennidad, a contracorriente de las tendencias de la civilización actual, caracterizada por lo fungible. Pueden evocarse las 10.000 grandes presas en funcionamiento on constuccion gues preses enveciendo $y$ reclaman los cuidados que esto enveriendo $y$ recla $y$ en constuccion servicio $y$ cos para $y$ ru perennidad. En la medida en que todas nuevas obras, grandes o pequeñs, son portadoras de riesgos ecológicos $y$, veces, catastróficos, que aumentan con el envejecimiento, la gerontolo que las presas es todo un emplazo. La accion adelantada de Arturo Rebollo en este terreno marca un camino a seguir para todos los que aman su propia obra con la devoción paternal que él ha puesto en Susqueda.

Un volumen encuadernado en cartoné plastificado con lomo de tela, de $18 \times 24,5 \mathrm{~cm}$, compuesto de 408 páginas, 330 figuras y fotografias y 39 tablas. Precios: 1.700 ptas.; extranjero, \$ USA 24.00 